[The Editors of the Journal of General Microbiology do not accept responsibility for the Reports of Proceedings. Abstracts of papers are published as received from Authors.]

\title{
The Proceedings of the Third Meeting of the North West European Microbiological Group held at Utrecht, 16-18 August 1971
}

\author{
Organized by The Netherlands Society of Microbiology
}

\section{SYMPOSIUM: MICROBIAL TAXONOMY}

\section{General Introduction. By S. T. Cowan (Queen Camel, Yeovil, Somerset, Great Britain)}

Taxonomy is concerned with relations and relationships, and the main purpose of the Symposium is to show how we determine and express them. Probably the most satisfactory method of showing a relationship is to prove the possibility of transfer of nuclear material from one organism to another; in practice we assess the degree of relatedness quantitatively by a statistical expression of the similarity of characters of the two organisms.

In classification it is usual to arrange microbes in a manner which brings together related organisms in groups of different rank; however, the hierarchy created does not indicate the course of evolution, neither is it a revelation of a Divine inspiration. Classifications are based on man-made concepts of units such as species and genera, but as the lower unit, species, cannot be defined or circumscribed, the hierarchy built on it resembles a house of straw. A modern concept of species accepts it as a population in a continuing state of multiplication; it cannot be represented by a single strain (as in the nomenclatural device to fix a name to a species) but only by several strains, so that the variability of the species and the limits of the characterization will be apparent. So-called 'intermediates' can be better accommodated in a taxonomic scheme dealing with populations than in a rigid hierarchical scheme of classical taxonomy.

Taxonomy is essentially subjective; non-taxonomists should not be overawed by loudly proclaimed and extravagant statements of taxonomic theory and practice. To show what can be done by an imaginative taxonomist, the Introduction to Taxonomy ended with an attempt to paint a surrealist impression of the microbial world that might be seen in a colour TV screen or in Alice's looking-glass.

\section{Problems of Nomenclature and Alternatives to Nomenclature. By S. P. LAPAGE (National Collection of Type Cultures, London NW9 5 HT, Great Britain)}

A means of referring to groups of living things is necessary for communication. Binary species names have largely proved satisfactory with eucaryotes and to a greater or lesser extent in the case of procaryotes, though forms of nomenclature may have limited forms of thought. Little practical choice of alternatives exists at present, perhaps codes as a supplement to names but not to supplant them. Human memory easily stores names, particularly if they have meaning, and less readily stores numbers, and as tests change so must codes, a practical inconvenience.

Future knowledge of microbes, particularly of their genetics and of their molecular structure, may alter our concept of the basic bacterial taxonomic unit, at present the species, and the relationships of these units, but until all is data-processed in the machine or forms of reference like chemical formulae can be used, some easy means of referring to the units will be required; even inorganic chemists still use names!

Alternatives to nomenclature would not alleviate many nomenclatural problems and a code of nomenclature (of whatever form) would still be required to deal with the problems of retroactivity, of the deposition of types in culture collections, of the registration of new names, of publication of lists of approved names, of the choice of a suitable starting date in bacteriology, of minimal standards of description in publications of new taxa and of the type of a taxon and its practical application.

These problems will be discussed with particular reference to the concepts of the drafting committee on the code which was established by the Judicial Commission (Commission (197I), Minutes of the Judicial Commission of the International Committee on Nomenclature of Bacteria, Minutes 28-39, International Journal of Systematic Bacteriology 21, 102) and whose concepts have been approved by the International Committee on Nomenclature of Bacteria (Commission (I97I), Minutes of the International Committee on Nomenclature of Bacteria, Minutes 15-17, International Journal of Systematic Bacteriology 2I, I I 4-I I 5, I I6-I I 7). 


\section{Typing of Micro-organisms in Relation to Taxonomy. By Hans LaUtrop (Diagnostic Bacteriology} Department, Statens Seruminstitut, Copenhagen, Denmark)

The historical development of some bacterial typing systems is sketched to illustrate the position of the units of the typing system in relation to the accepted species at the time they were developed. Some of the serotypes were equated with new bacterial species, others were recognized as subdivisions of an existing species. The immunochemical basis of the Enterobacteriaceae serotypes and the complex basis underlying phage types are mentioned. It is shown that the position of the typing units as infrasubspecific forms in the present International Code of Nomenclature of Bacteria is arbitrary because their ranking within the linearly branched subdivisions of a major group of bacteria depend on which of the levels of subdivision is decided on as the specific level, and this in bacterial classification is still an arbitrary decision.

\section{A Molecular Approach to Microbial Taxonomy. By J. DE LeY (Lab. voor Microbiologie, Ghent, Belgium)}

Current methods concern largely structural aspects of DNA. Within the foreseeable future other molecular species, such as protein and RNA structure, will be involved. Techniques for measuring genome size (from chemical estimation, electron microscopy, autoradiography or renaturation rates), DNA base composition (from chemical estimation, buoyant density, thermal denaturation, etc.) and DNA base sequence comparison (agar and filter methods, renaturation rates, etc.) are very powerful, but require important equipment, a technically skilled staff, a sound knowledge of molecular biology and a critical evaluation of these methods and their interpretation. DNA base composition is known for several thousands of micro-organisms and its contribution to taxonomy is considerable.

Methods for measuring DNA genome size foreshadow applicability perhaps only at higher hierarchical levels.

DNA hybridization methods will certainly help to unravel the evolution of bacteria. The agreement between molecular and phenotypic taxonomy depends on the degree of evolutionary divergency of the organisms.

Metabolic Pathways and Taxonomy of Pseudomonas and Acinetobacter. By N. J. PALLERONI (Department of Bacteriology and Immunology, University of California, Berkeley, California, U.S.A.)

Comparative biochemical studies performed on strains belonging to the genera Pseudomonas and Acinetobacter by the Berkeley group have shown that closely related organisms use identical pathways for the degradation of various organic compounds, while bacteria belonging to distant groups may follow either similar or different pathways.

The control mechanisms by which the cells regulate the synthesis of enzymes involved in the operation of inducible pathways often provide additional clues for the understanding of the relationships among groups of bacteria. Examples to illustrate this point are taken from studies on control mechanisms in the degradative pathways of aromatic compounds.

The use of the same biochemical pathway by unrelated organisms can be regarded as the result of a common evolutionary origin. Alternatively, the situation could reflect biochemical convergence, i.e. the pathway adopted may simply be one of the few 'practical' ways of performing the biochemical transformations.

At present it is impossible to decide in favour of either hypothesis in the case of the examples presented. For the moment, it is safe to assume that the use of identical pathways and control mechanisms suggest close relationship between two organisms, particularly when genetic evidence points to similar location of the genes in the bacterial chromosome. 


\title{
Numerical Taxonomy in Microbial Classification. By H. G. Gyllenberg (Helsingin Yliopisto Mikrobiologian Laitos, Helsinki, Finland)
}

During the fourteen years which have elapsed since Sneath published his first papers on the application of numerical taxonomy to micro-organisms, a tremendous amount of information has accumulated in this field. Numerical methods of classification are now well known and there are widely utilized standard routines. Therefore, a detailed survey of numerical taxonomy in microbial classification is of less interest than a discussion of the impacts of numerical classification on microbiology in general and on the diffusion of the basic ideas of the numerical approach into new fields of microbiology.

A general analysis of numerical taxonomy in relation to usual classification techniques indicates that numerical taxonomy is one expression of the principle of microbial classification which proceeds from the level of individual organisms to a system of classes and groups of different hierarchical ranks. On the level of species, numerical taxonomy provides one possible way to recognize taxospecies, which according to Ravin can be considered as tight phenetic clusters which are formed by grouping together individual strains that have a high proportion of characters in common.

Looking for the impacts of numerical taxonomy on our microbiological thinking main emphasis can thus be allotted on the practical application of the taxospecies concept. Such applications, which will be discussed in some length in the full paper, can be found in microbiological patents, in approaches to automatic identification of micro-organisms, and by analogy in the attempts to numerical analysis of microbial populations. The taxospecies also provide attractive targets for an analysis of the patterns of correlated characteristics in micro-organisms. Analytic techniques of this kind seem to be useful tools for the interpretation of the mutual relations of taxospecies created by numerical classification or by equal methods.

Two aspects will be particularly emphasized in the full paper. First, the possibilities for a more general application of numerical taxonomy to practical problems in microbiology, and secondly, the available methods for extraction of the information inherent in numerical classifications. As far as the second point is concerned, it constitutes an important challenge to the numerical taxonomists. Although numerical taxonomy has contributed most significantly to microbial systematics, there is an obvious danger that it will lose interest due to the somewhat abstract and schematic approach. Therefore, any effort to integrate numerical taxonomy into a generalized taxonomic theory and practice would be indicative of great progress. The perspectives for success of this task are very promising.

\section{SYMPOSIUM: AUTOTROPHY}

\author{
The Demise of the Obligate Autotroph. By Sydney C. Rittenberg (Department of Bacteriology, \\ University of California, Los Angeles, California, U.S.A.)
}

Autotrophy is a life style in which inorganic compounds provide for all nutritional needs of an organism. Implicit in this definition is the capacity of an organism to derive all cell carbon from $\mathrm{CO}_{2}$ and to obtain ATP either photosynthetically or chemolithotrophically. The existence of bacteria with such potentials has been known since the work of Winogradsky in the I880s. The question explored in this paper is whether bacteria exist that must of necessity live autotrophically, i.e. the obligate autotroph senso Winogradsky.

It has long been known that phototrophy and autotrophy are not necessarily coupled; e.g. as in the Athiorhodaceae. Likewise, chemolithotrophy and autotrophy need not be coupled. Desulfovibrio desulfuricans and Thiobacillus perometabolis can utilize hydrogen and reduced inorganic sulphur compounds, respectively, as energy sources. Neither organism can grow autotrophically. Thiobacillus intermedius, which can grow autotrophically, also grows with a reduced inorganic sulphur compound providing all energy and glucose, or other organic molecules, providing over $80 \%$ of cell carbon.

The concept that autotrophic bacteria are uniquely inhibited by organic matter seems no longer tenable. The repression of ribulose diphosphate carboxylase by organic compounds has been demonstrated in both photosynthetic and chemolithotrophic bacteria. Likewise, the repression of hydrogenase and the thiosulphate oxidase system by organic compounds is known. These inhibitory 
effects appear similar to catabolite repression in heterotrophic bacteria. Inhibition of bacteria growing autotrophically by normal metabolites is also known. Recent studies indicate that for L-amino acids, at least, these inhibitions are based on feedback inhibition of biosynthetic pathways, a normal regulatory process in heterotrophic organisms.

All putative obligate autotrophs tested to date, including both photosynthetic and chemolithotrophic species, assimilate significant quantities of exogenously supplied organic metabolites. Individual amino acids, tricarboxylic acid cycle compounds and acetate, or complex mixtures such as yeast extract, may contribute, under appropriate conditions, 10 \% or more of the cell carbon. Assimilated carbon from certain compounds may be widely distributed among the major cell components.

The ability to utilize an individual organic compound for a few per cent of the total cell carbon implies that heterotrophic and autotrophic biosynthetic processes can occur concomitantly within a cell. It has also been shown that hydrogenomonads and some thiobacilli can be mixotrophic with respect to energy generation.

Examples remain of bacteria that have not been cultured in the absence of an inorganic energy source or light. Such forms are appropriately described as obligate chemolithotrophs or obligate phototrophs. The available evidence, briefly categorized above, suggests that none of these bacteria is, at the same time, an obligate autotroph. From ecological and evolutionary considerations, an absolute dependence on carbon dioxide for all carbon makes little sense and bacteria with such a requirement would be an anachronism on earth as it now exists.

Electron Transport in Chemolithotrophic Micro-organisms. By M. I. H. ALEEM (Department of Microbiology, University of Kentucky, Lexington, Kentucky, U.S.A.)

High efficiency of oxidative phosphorylation was observed with respective inorganic electron donors in the chemolithotrophs Nitrobacter, Thiobacillus species, and various hydrogenomonads. Nitrobacter agilis and Thiobacillus neapolitanus were unable to grow on organic compounds and lacked $\alpha$-ketoglutarate dehydrogenase. Nitrobacter, however, catalysed oxidative phosphorylation with NADH, exhibiting similarities with the mitochondrial systems, whereas the oxidation of NADH in T. neapolitanus was not coupled to phosphorylation and it was also relatively insensitive to respiratory chain inhibitors. In the facultative autotroph Thiobacillus novellus, NADH oxidation involved all of the three coupling sites for ATP generation which was catalysed by a non-particulate cell-free fraction $144,000 \mathrm{~g}$ supernatant. The same fraction catalysed oxidative phosphorylation as well as the energy-linked reduction of pyridine nucleotides with thiosulphate or sulphide which entered the respiratory chain at the cytochrome $c$ or the flavin-level respectively. The acid-induced ATP formation in $T$. novellus, in the absence of added substrates, occurred in frozen cells or their extracts, which were incapable of catalysing oxidative phosphorylation; the proton-induced ATP formation was inhibited by uncouplers but not by respiratory chain inhibitors. Thus the acid-induced phosphorylation was not linked to the electron transport system and the phenomenon, moreover, did not occur in non-particulate supernatant.

The electron transport from $\mathrm{H}_{2}$ to $\mathrm{O}_{2}$ in Hydrogenomonas eutropha was mediated by the pyridine nucleotides and involved all of the coupling sites for ATP generation with either $\mathrm{H}_{2}$ or NADH as the electron donor. In autotrophically grown Micrococcus denitrificans about $60 \%$ of the electrons from $\mathrm{H}_{2}$ by-passed pyridine nucleotides and involved coupling sites II and III for ATP generation. In autotrophically grown Pseudomonas saccharophilia virtually all of the electrons from $\mathrm{H}_{2}$ by-passed pyridine nucleotides. While the NADH-linked phosphorylation involved coupling sites I and II, $\mathrm{H}_{2}$ oxidation in $P$. saccharophilia was coupled to phosphorylation at site II only. Site III was nonfunctional in autotrophic cells but was functional in heterotrophically grown organism. 


\section{A Speculative Discussion of the Relationship of Methane-oxidizing Bacteria to Chemolithotrophs. By R. WHITTENBURY (Department of General Microbiology, University of Edinburgh, Edinburgh, Great Britain)}

The untimely death of Derek Hoare, who was to present a paper leading into this subject, has left a gap in the development of this theme. However, I shall try to present a paper along the lines he and I discussed.

To relate methane oxidizers to chemolithotrophs requires some special pleading, some fact, and a fertile imagination. The special pleading relates to the defining of chemolithotrophy to fit the argument that methane oxidizers are classifiable in that category. The factual area relates to the present-day knowledge of the methane-oxidizing bacteria and the imagination, a stumbling block, is to be applied in speculating about the methane-oxidizing process and the relationship of the methane oxidizers in function and structure to particular chemolithotrophs.

In strict terms methane oxidizers are not chemolithotrophs as they only use organic energy sources and derive the major part of their cell carbon from organic $\mathrm{C}_{1}$ compounds, some being fixed from carbon dioxide by a non-autotrophic process.

Morphologically, structurally and physiologically, the methane oxidizers divide into two distinctive and apparently unrelated groups of bacteria. One group resembles Azobacter species in many features, though not in nitrogen-fixing powers, whilst the other group resembles no previously described bacteria. These groups and their subgroups (species?) will be described and their relationship to organotrophs mentioned before moving on to their chemolithotrophic affinities.

Although all methane oxidizers appear to follow a similar enzymic route in the oxidation of methane to carbon dioxide, they differ in their mode of carbon assimilation. Formaldehyde appears to be the point in the oxidation route of methane at which carbon is diverted into cell synthetic systems. One of the groups (the Azotobacter-like group) fixes formaldehyde via the allulose phosphate pathway, whilst the other does so via the serine pathway. Arguments on the similarity of methane oxidizers to chemolithotrophs are developed from this juncture. Similarities in metabolic patterns are discussed and extended to structural similarities (membrane systems) which methane oxidizing bacteria appear to have in common with the nitrifying bacteria.

Prior to this speculation, the distinctive properties of chemolithotrophs will be presented in a form to fit the arguments that they and the methane oxidizers are similar in principle.

Mechanisms of Photosynthesis. By L. N. M. Duysens (Laboratorium v. Biofysica, Schelpenkade I4A, Leiden, The Netherlands)

The electron transport chain of photosynthesis of algae and higher plants is represented by the following scheme:

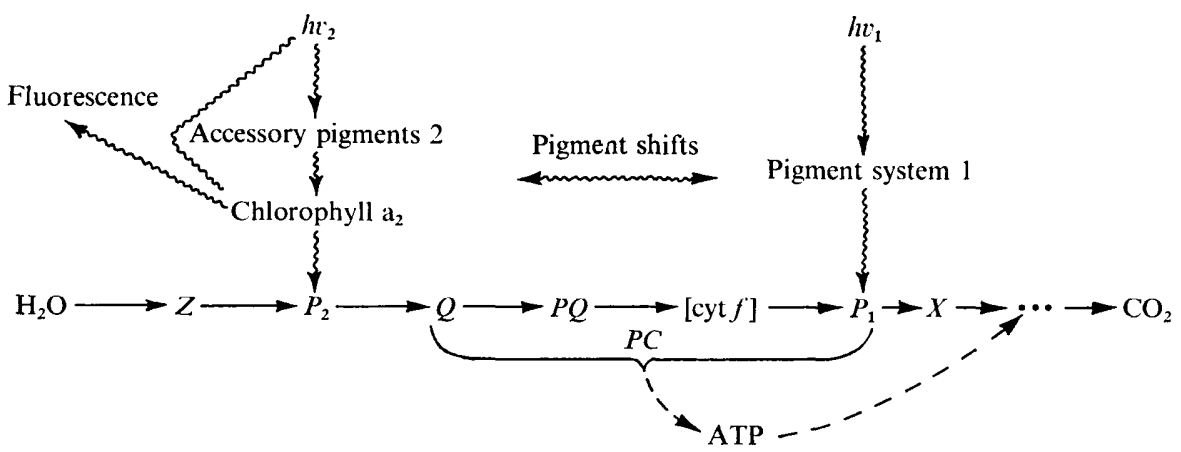

The arrows indicate the electron transport. The light is absorbed by the pigment molecules of system $I$ and 2, and the excitation energy is transferred to the photochemically reacting chlorophyll molecules $P_{2}$ and $P_{1}$, which occur in a small concentration. This concentration is of the order of $\mathrm{I} \%$ or smaller. The photochemically active $\boldsymbol{P}_{2}$ and $\boldsymbol{P}_{1}$ transfer upon excitation an electron to the primary 
acceptors $Q$ and $X$. As a consequence of this primary reaction $P_{2}^{+}, P_{1}^{+}, Q^{-}$and $X^{-}$are formed. $P_{2}^{+}$ oxidizes $Z$ and $P_{1}^{+}$oxidizes cytochrome. Between $Q$ and $P_{1}^{+}$phosphorylation takes place. $X^{-}$reduces $\mathrm{CO}_{2}$ via the components of the Calvin cycle, for which ATP is needed. $Z^{+}$oxidizes water, giving oxygen and protons. In photosynthetic bacteria photoreaction 2 is missing. Instead of $P_{1}$ a chemically active bacteriochlorophyll is present, and cytochrome oxidizes an added hydrogen donor, such as $\mathrm{H}_{2} \mathrm{~S}$.

It will be discussed how components and processes represented in this scheme have been identified and studied.

\section{Nitrogen Fixation in Photosynthetic Micro-organisms. By P. FAY (University of London, London, Great Britain)}

The biochemical mechanism of $\mathrm{N}_{2}$ fixation in photosynthetic micro-organisms is similar to that which operates in heterotrophic bacteria with respect to the main characteristics like the requirement for energy and for electron donors, the response to inhibitors, the extreme sensitivity to free $\mathrm{O}_{2}$ or the versatility of catalysing the reduction of alternative substrates. The secondary characteristics of the $\mathrm{N}_{2}$-fixing system show, however, great variations according to the metabolic type of the organism concerned. In photosynthetic $\mathrm{N}_{2}$-fixing micro-organisms both energy and reducing power are normally generated in the photochemical reaction, and the carbon pool to incorporate the fixed nitrogen is produced in photosynthesis. While in photosynthetic bacteria these requirements are provided under anaerobic conditions essential for the synthesis and function of nitrogenase, in blue-green algae photosynthesis creates an aerobic cellular environment by the concomitant release of free $\mathrm{O}_{2}$. The evolutionary adjustment enabling the simultaneous operation of the two processes $\mathrm{O}_{2}$-evolving photosynthesis and $\mathrm{O}_{2}$-sensitive $\mathrm{N}_{2}$ fixation might have been a gradual process, in the course of which a variety of correlative systems have arisen. The most successful adaptation to the present-day predominantly aerobic conditions appears to be the separation, by cell differentiation, of the two metabolic activities in the heterocystous blue-green algae. Heterocysts not only provide optimum conditions for the maintenance of nitrogenase activity but also retain a modified photochemical apparatus capable of photophosphorylation and of light dependent cytochrome oxidation. Evidence suggests that the process of differentiation and also the interrelations between the carbon assimilating vegetative cells and the $\mathrm{N}_{2}$-fixing heterocysts are controlled by a mechanism registering the changes of the $\mathrm{C}: \mathrm{N}$ ratio of the organism.

\section{Taxonomy of the Photosynthetic Bacteria. By N. Pfennig (Institut für Microbiologie der Universität, Göttingen, Germany)}

The historical basis of the taxonomy of the three physiological-ecological groups of photosynthetic bacteria given by van Niel (Bergey's Manual, 7 th ed., 1957) is presented. The species descriptions of the purple non-sulphur bacteria (Athiorhodaceae or Rhodospirillaceae) are based on the detailed study of larger numbers of pure culture isolates and therefore represent the best defined groups. In contrast, the basis of the taxonomy of the purple and green sulphur bacteria (Thiorhodaceae or Chromatiaceae and Chlorobiaceae) are the classical morphological descriptions of cell material collected in nature. The few strains of each species isolated so far in pure culture are at present classified on the basis of the morphology of the individual cells and the morphological resemblance to the existing species descriptions. As a result, the present system will be subject to alterations when cytological and biochemical studies (including DNA-base ratios and DNA-base homology studies) of a larger number of isolates of each taxon can be evaluated for the establishment of species and genera. The green sulphur bacteria are well defined as a group since their photopigments (major bacteriochlorophylls: $c$ or $d$, carotenoid chlorobactene) are not located at unit membrane-type structures (as it is true for all other photosynthetic organisms) but contained in unique organelles the chlorobium vesicles - which are physically distinct but attached to the cytoplasmic membrane. 
Ecology of Photosynthetic Bacteria. By H. van Gemerden (Lab. voor Microbiologie, Haren (Gr.), The Netherlands)

The classification of photosynthetic bacteria is in part based upon their behaviour towards hydrogen sulphide.

Among the environmental factors which control the activity of photosynthetic bacteria (sulphide concentration, light intensity and spectral light distribution, growth factors, oxygen, etc.), sulphide is of utmost importance. Sulphide may be utilized as electron donor in photosynthesis, but may be inhibitory for growth as well. The relation between the specific growth rate and the sulphide concentration is thus represented by an optimum curve, characterized by the saturation constant $K_{\mathrm{B}}$ and the inhibition constant $K_{\mathrm{i}}$ (lowest, respectively highest sulphide concentration at which $\mu$ equals $\left.\frac{1}{2} \mu_{\max }\right)$, the maximum specific growth rate attainable, and the arbitrary sulphide tolerance (highest sulphide concentration at which growth occurs within a reasonable period of time).

Typical values for a Chromatium grown at light saturation intensities are: $K_{\mathrm{s}} 0.007 \mathrm{mM} ; K_{\mathrm{i}} 0.9 \mathrm{~mm}$; $\mu_{\max } 0.12 \mathrm{~h}^{-1}$; sulphide tolerance $2 \cdot 2 \mathrm{mM}$. However, some strains still grow at sulphide concentrations of $8 \mathrm{~mm}$. The occurrence of environmental sulphide concentrations exceeding the sulphide tolerance for a given strain does not imply that the organisms are completely inactive. Under such conditions no growth occurs but sulphide may still be oxidized accompanied by the production of storage polymers. The same phenomenon is observed after a dark-light shift.

It has been found that purple non-sulphur bacteria are more sensitive to sulphide than purple sulphur bacteria. Moreover, the former should not be able to utilize sulphide as electron donor. However, such phenomena could also be explained as the result of a very low $K_{\mathrm{i}}$ value as compared to that of purple sulphur bacteria. The data so far collected by growing purple non-sulphur bacteria at very low sulphide concentrations (continuous cultures with sulphide as growth-limiting factor), do indeed support the hypothesis that sulphide may act as sole electron donor for all photosynthetic bacteria.

Green and purple sulphur bacteria play an important role in the sulphur cycle of anaerobic aquatic environments; it may well be that the contribution of the purple non-sulphur bacteria to the sulphur cycle has been underestimated in the past.

\section{ORIGINAL PAPERS}

DNA-base Ratios of Bacillus Strains Related to Numerical and Classical Taxonomy. By G. J. BondE and D. K. JACKSON (Institute of Hygiene, University of Aarhus, Aarhus, Denmark)

A collection of 378 Bacillus strains was examined by 64 tests, 22 morphological and 32 biochemical criteria. Forty-eight strains were from collections, 330 were isolated from canned foods, faeces, water, sewage, soil, dust and mud (Bonde (1965), Journal of General Microbiology 4I, 4I6).

The tests applied were mainly those of Smith, Gordon \& Clark (Aerobic spore-forming bacteria, U.S. Department of Agriculture Monograph, no. 16, Washington D.C., supplemented with some from Bonde (Bacterial Indicators of Water Pollution, Copenhagen (1962)). Numerical classification was performed by a single-linkage clustering programme and classification by the dichotomous keys of Smith et al. (1952), and of Gibson-Topping ((1938), Proceedings of the Society of Agricultural Bacteriologists, p. 43) by a sorting programme, both in ALGOL.

The phenetic classification resulted in the differentation of six major and two smaller groups. The key classifications divided the strains into I4 species.

DNA-base composition of 99 strains, including 27 type-strains, were examined by the methods of Marmur ((196I), Journal of Molecular Biology 3, 208) and Marmur \& Doty ((1962), Journal of Molecular Biology 5, I09). Good yields were generally obtained in simple media, sometimes after addition of vancomycin $\mathrm{HCl}$ (Lilly). The estimation of denaturation-temperature being a doseresponse relationship, $T_{\mathrm{m}}$ 's were also computed after a Probit transformation, which will give a correction for bad graphs, and an estimate of standard deviation.

The measurements might be graded according to magnitude of $T_{\mathrm{m}}$ in four groups, A-D, all data being well approximated by the normal distribution. Considerable overlapping was found of groups B-D. Only group A (GC\%:36-39) is homogeneous, comprising phenetic group IIC (cereus strains). Group B was constituted mostly by sphaericus strains (37 to 45 ). Group C is constituted by the 
overlapping of several phenetic and taxonomic groups: IVB (pumilus, 44-45), IIB (megaterium, 42 to 46 ), and III A + IVA (subtilis, 46 to 48 ). Group D was dominated by V (licheniformis strains, 45 to 50 ).

The GC ratios of the type-strains, cereus $36 \cdot 8$, sphaericus $39 \cdot 4$, pumilus $44 \cdot 6$, megaterium $45^{\circ} 0$, subtilis $47 \cdot 5$ and licheniformis $49 \cdot 6$, agree with the group means, and with the data of Hill ((1966), Journal of General Microbiology 44, 419).

With the exception of group A, none of the other DNA-groups has a distinctive set of characters. However, a rise in GC values is accompanied by certain trends (e.g. fermentation of more sugars).

In view of the considerable error attributed to single determination of $T_{\mathrm{m}}$ and the normality of data it is recommended to calculate GC values from arithmetic averages of more estimates of $T_{\mathrm{m}}$. As no association is found between distinctive characters of phenetic and diagnostic groups and the GC ratios the latter are not of crucial value for classification but may be helpful in adding one more character.

\section{A Taxonomic Study of Pasteurella and Actinobacillus Strains. By W. FrederIKSEN (Statens Serum- institut Regional Department, Aalborg, Denmark)}

The study comprised strains from collections, from other workers, as well as strains isolated in Statens Seruminstut.

Strains allocated to Pasteurella multocida can be separated into six biotypes by their pattern of fermentation of L-arabinose, D-xylose, maltose and trehalose. One biotype is further characterized by its inability to ferment sorbitol and mannitol; it includes several strains isolated from healthy dogs by J. Smith.

Strains labelled Pasteurella pneumotropica form three biotypes, separated according to their fermentation of L-arabinose, D-xylose, trehalose and melibiose, as well as to their production of $\beta$-galactosidase, lysine and ornithine decarboxylase. One biotype comprises a strain originally isolated by E. Jawetz, and strains isolated by W. G. Hoag, P. W. Wetmore, J. Rogers and H. Meier. The second biotype comprises the strains isolated by J. G. Heyl and strain ATCC I 2555. The third biotype consists of two strains isolated by S. D. Henriksen from man, three other human isolates, and strains from cats. Strains called Pasteurella ureae received from Henriksen and Jones form a homogeneous group, indistinguishable from similar strains isolated in the U.S.A. and in Denmark. They have so far been found only in man.

Pasteurella haemolytica has been divided into two types, 'A' and 'T', by G. R. Smith. Strains received from Smith can be separated into two groups according to the fermentation of mannose, cellobiose, trehalose, and salicin; type ' $T$ ' producing acid from all of them, type ' $A$ ' from none. However, the number of strains examined is small. Strains labelled Pasteurella gallinarum can be placed with $P$. haemolytica as a sorbitol-mannitol-negative biotype.

Actinobacillus lignieresii and $A$. equuli differ in their fermentation of trehalose and melibiose. Strains isolated from swine differ from the aforementioned in producing acid from L-arabinose, cellobiose, salicin and aesculin. They have been called $A$. suis.

Differentiation of Mycobacterium rhodochrous and Runyon's Group IV Mycobacteria using Numerical Taxonomic Techniques. By M. Goodfellow, A. Fleming (University of Newcastle upon Tyne, Newcastle upon Tyne) and M. SACKIN (University of Leicester, Leicester, Great Britain)

The rhodochrous group forms a tight phenetic cluster but its generic location is still unsettled (Goodfellow, M. (1971) Journal of General Microbiology 69, 33). Representatives of the rhodochrous group were compared with 70 strains of fast-growing mycobacteria received carrying over 20 specific epithets. The cultures were examined for 175 morphological, biochemical, inhibition and nutritional characters and the quantitative relationships between them assessed using the matching coefficient (Sokal, R. R. \& Mitchener, C. D. (1958) Kansas University Science Bulletin 38, 1409). Cluster analysis was by the unweighted average linkage method (Sokal, R. R. \& Sneath, P. H. A. (I963), Principles of Numerical Taxonomy, W. H. Freeman \& Co., San Francisco).

At the $75 \%$ phenon level the rhodochrous strains were recovered as a distinct cluster sharply separated from a second cluster containing the Group IV mycobacteria. The mycobacteria fell into 
6 subgroups defined at the $85 \%$ S level; (3A) M. abscessus, M. borstelense, M. chitae, M. gallinarum, $M$. piscium and $M$. runyonii; (3B) $M$. aurum, $M$. diernhoferi, $M$. parafortiutum and $M$. vaccae; (3C) M. fortiutim, M. minetti, M. platypoecilus and M. salmoniphilum; (3D) M. butyricum, M. giae, $M$. ranae and $M$. smegmatis; $(3 \mathrm{~F})$ N. rubra; $(3 \mathrm{G})$ N. pellegrino. Although clusters and taxospecies cannot be directly equated it would appear that considerable overspecification has occurred among the rapidly growing mycobacteria.

The rhodochrous strains can be readily distinguished from the fast-growing mycobacteria. They alone were able to grow on media containing sodium adipate, citrate, gluconate, succinate and paraffin as a sole source of carbon, were inhibited by Io i.u. of penicillin but able to grow at $10^{\circ}$. Alternatively only the mycobacteria were strongly acid-fast, grew at $\mathrm{pH} 5$ and hydrolysed Tween 80 .

The rhodochrous group can be sharply separated from the fast-growing mycobacteria and should be excluded from the genus Mycobacterium and provisionally placed in the genus Nocardia. Further work is required to determine whether the rhodochrous group should be recognized as a genus and to quantify the relationship of the taxon with diphtheroid bacteria, particularly Arthrobacter.

\section{Genetic Relatedness within the Bacillus cereus group of Bacilli. By H. J. SOMERVILLE and M. L. JONES (Shell Research Limited, Borden Microbiological Laboratory, Sittingbourne, Kent, Great Britain)}

The present study using DNA-DNA hybridization was carried out to determine the relationships between different strains of Bacillus thuringiensis and between $B$. thuringiensis and the aerobic spore-formers which have been shown to be closely related to $B$. thuringiensis by other criteria (Smith, N. R., Gordon, R. E. \& Clark, F. E. (1952), U.S. Department of Agriculture Monograph no. 16). The $B$. thuringiensis group of crystal-forming bacilli has been divided into about $10-12$ strains which can be separately identified by comparison of biochemical properties or by serology (de Barjac, H. \& Bonnefoi, A. (1962), Entomophaga 7, 233; Norris, J. R. \& Burges, H. D. (1965), Entomophaga 10, 4I).

DNA was prepared from Bacillus thuringiensis (13 strains), Bacillus cereus (4 strains), Bacillus anthracis (2 non-pathogenic strains), Bacillus megaterium (5 strains), and Bacillus subtilis and Bacillus licheniformis (I strain each). Radioactive DNA was prepared from exponential-phase cultures to which $\left[{ }^{14} \mathrm{C}\right]$ adenine was added approximately $30 \mathrm{~min}$. (half a generation) before harvesting. In most cases, hybridizations were carried out at $60^{\circ}$ for $16 \mathrm{~h}$. under conditions described by Johnson and Ordal (Johnson, J. L. \& Ordal, E. J. (1968), Journal of Bacteriology 95, 893) using reference strains from B. thuringiensis (6), B. cereus (I), B. megaterium (2) and B. anthracis (1). Results calculated as percentage competition (Palleroni, N. J., Doudoroff, M., Stanier, R. Y., Solanes, R. E. \& Mandel, M. (1970), Journal of General Microbiology 6o, 215) showed that, although the pattern of relatedness was consistent from experiment to experiment, the percentage competition in duplicate determinations varied by as much as $15 \%$ of the full scale and in reciprocal experiments varied by as much as $30 \%$ of full scale. All $B$. thuringiensis strains showed more than $45 \%$ competition by intra-species hybridization; the average competition was in the range $65-85 \%$ in this set of determinations. The results of inter-species hybridization experiments showed a wide range of competition (13-100\%) between B. anthracis, B. cereus, B. thuringiensis and B. megaterium.

Analysis of the results suggests that $B$. thuringiensis is more closely related to $B$. anthracis than to $B$. cereus. All three of these species are closely related to each other. Strains of $B$. megaterium appear to differ over a wider range than within the above three species. Only limited competition was observed between DNA from these four species and either $\boldsymbol{B}$. subtilis or $\boldsymbol{B}$. licheniformis.

\section{Bacterial Identification by Gas-Liquid Chromatography. By D. B. DruCKer and I. Owen (University of Manchester, Manchester, Great Britain)}

Gas chromatography has been applied to microbiology in order to investigate existing classifications and to make rapid identification of bacteria a possibility. The use of pyrogram 'fingerprints' has been suggested by Reiner ((1965), Nature 206, 1272) whilst attempts have also been made to analyse fermentation products or volatile derivatives of cellular fatty acids, amines or sugars. An ambitious gas chromatographic grouping of bacteria has been undertaken by Ueta et al. (Ueta, Ishizuka \& Yamakawa (1970), Culture Collections of Micro-organisms, pp. 371-38I), although most workers have studied species of a single genus only. We have attempted to compare repre- 
sentatives of several genera grown under carefully controlled conditions of growth in order to see whether genera do display genuinely different G.L.C. 'fingerprints', since differences have been shown to be caused by changes in culture age, incubation temperature, nutrition and Eh.

Various species including closely related strains were studied. Test organisms, including species of Bacillus, Corynebacterium, Escherichia, Klebsiella, Neisseria, Pseudomonas, Serratia, Staphylococcus and Streptococcus, were dried in vacuo over $\mathrm{P}_{2} \mathrm{O}_{5}$. Ten mg. aliquots were heated to $100^{\circ}$ for $3 \mathrm{~h}$. with $\mathrm{BF}_{3} / \mathrm{CH}_{3} \mathrm{OH}$ in sealed ampoules. The contents of ampoules were washed, extracted in petroleum spirit $\left(40-60^{\circ}\right)$ and concentrated. Separations were performed at $192^{\circ}$ on a glass column packed with 10\% PEGA on I00- to I20-mesh Celite.

The 'fingerprint' tracings obtained showed that the difference between the fatty-acid profiles of $B$. megaterium and $E$. coli was less than that which could be obtained by manipulating the environment of either organism. All organisms tested, other than streptococci, had very similar fatty-acid profiles when grown under standard conditions; however, G.L.C. of methyl esters of cellular fatty acids appears to be of considerable value for distinguishing between selected closely related strains, e.g. certain oral streptococci which have very characteristic fatty-acid profiles.

\section{Aids in Classification and Characterization of Neisseria Species. By D. IVLER (University of Southern California School of Medicine, Los Angeles, U.S.A.)}

More than 350 strains of $N$. meningitidis, grown on translucent agar media, have been examined with a dissecting microscope and compared with 23 strains of $N$. gonorrhoeae, representative strains of non-pathogenic Neisseria, and 65 strains of $N$. lactamicus. Many of the non-pathogenic Neisseria produce colonies that have dentate edges and/or pigmentation, whereas the meningococcal colonies are entire and non-pigmented. Approximately $90 \%$ of group Y meningococcal strains can be identified as such due to their characteristic growth in larger colony size and concentric rings. Fresh isolates of $N$. meningitidis can usually be differentiated from the 'laboratory cultures' in that they are translucent and homogeneous without 'internal structure', whereas strains that have been subcultured eight or more times have a frosted appearance and show 'internal structures' and concentric rings of growth. Colonial types of the gonococci ( $\mathrm{T}_{1}, \mathrm{~T}_{2}, \mathrm{~T}_{3}$ and $\mathrm{T}_{4}$ ) can be further differentiated with the dissecting microscope. Colonies can be picked that do not auto-agglutinate in saline and that show no cross-reactions with meningococcal typing sera. This approach shows promise in establishing a distinct serological classification for $N$. gonorrhoeae. The increasing frequency of isolation of $N$. lactamicus from pharyngeal swabs obtained during $N$. meningitidis carrier surveys calls for reliable, simple, rapid tests to provide criteria for distinguishing between these two related species. All the lactose-fermenting strains show a marked increase in yellow pigment production when grown on agar media containing $0.02 \%$ cystine, whereas the meningococci do not. Published reports have indicated that only $30 \%$ of the $N$. lactamicus could be serogrouped with specific antisera, because the majority of the strains auto-agglutinated. The problem of autoagglutination can be eliminated by increasing the molarity of the saline. This increased saline concentration has allowed all isolated lactose-fermenting Neisseria to be serogrouped.

The Classification of a Multicellular Bacterium Isolated from Activated Sludge. By W. L. VAN VEEN, D. VAN DeR KooIJ, A. C. B. A. GeUZe and A. W. vAN DER Vlies (Lab. voor Microbiologie, de Lanbouwhogeschool, Wageningen, The Netherlands)

The phenomenon of filamentous bulking of activated sludge has often been associated with Sphaerotilus natans. The bacterial filaments in the flocs are thought to interfere with clumping and rapid settling of the flocs.

Recently Pasveer and Farquhar \& Boyle tried to identify a number of different multicellular bacteria from activated sludge, but did not obtain pure cultures.

The present authors developed a procedure to isolate a variety of multicellular bacteria. With phase-contrast and electron microscopy the morphological features of the bacteria originally present in the sludge were compared with those of the final isolates.

Special attention was given to a thin-sheathed bacterium, which appeared to be closely related to or identical with a micro-organism described as Streptothrix hyalina by Migula (( 1895), in Engler, A. \& Prantl, K. (1900), Die natürlichen Pflanzenfamilien, I, I a, W. Engelmann, Leipzig, pp. 35-40).

The dimensions of the small-sheathed bacterium are $0.35-0.45 \mu \mathrm{m}$. by $3.2-5 \mu \mathrm{m}$. Cells outside 
the sheaths are non-motile. Branching of sheaths incidentally occurs in stationary cultures. Holdfasts are never observed. Colonies have a pinkish appearance, due to the presence of carotenoid pigments. The cells do not contain poly- $\beta$-hydroxybutyrate. Ferric or manganic oxides are apparently not deposited on the sheaths. Glucose, sucrose, lactose and to a lesser extent mannitol are excellent carbon sources, but not sorbitol, glycerol, lactate, $\beta$-hydroxybutyrate, acetate and succinate. Vitamin B I 2 and thiamine are required for growth.

Due to the above-mentioned properties, which differ greatly from those of S. natans, the classification of this small bacterium in a separate genus, Streptothrix gen.nov., is proposed.

\section{Taxonomic Significance of Citrate Synthase. By Dorothy Jones and P. D. J. Weitzman (Leicester,} Great Britain)

In previous work we have reported that the regulatory and molecular properties of bacterial citrate synthases can be correlated with the taxonomic grouping of bacteria. The activity of citrate synthase is regulated through end-product inhibition by NADH only in the Gram-negative bacteria. Within this group the inhibition by NADH is overcome by AMP only in the strict aerobes. Moreover Gram-negative bacterial citrate synthases are 'large' enzymes (mol. wt. 250,000) while the Gram-positive enzymes are 'small' (mol. wt. < 100,000 ). We have made use of these clear distinctions to assist in the taxonomy of a number of bacteria where the classification has been, or is, in doubt. The citrate synthases of Pseudomonas iodinum, Achromobacter liquefaciens and Haemophilus vaginalis were not inhibited by NADH and were found by gel filtration to be of the 'small' type, indicating that they belong to the Gram-positive area. Pseudomonas formicans citrate synthase was inhibited by NADH and not reactivated by AMP and was of the 'large' type, indicating that this organism is related to the Enterobacteriaceae. The classifications indicated by our data will be discussed in relation to the recent studies with these bacteria. The agreement in results supports the taxonomic significance of citrate synthase.

\section{The Taxonomy of the Pseudomonas fluorescens Species Group. By Muriel E. RHODES (University College of Wales, Aberystwyth, Great Britain)}

The Rhodes Collection of aerobic fluorescent pseudomonads was re-examined with especial emphasis on the diagnostic criteria selected by Stanier, R. Y., Palleroni, N. J. \& Doudoroff, M. (1966), Journal of General Microbiology 43, I59-27I, for the differentiation of the three species $P$ seudomonas aeruginosa, $\boldsymbol{P}$. fluorescens and $\boldsymbol{P}$. putida. The three species categories could not be upheld; far too many 'intermediate types' were revealed, linking the isolates into a continuous series as before (Rhodes, M. E. (I96I), Journal of General Microbiology 25, 33I-345). Some of the key characters are discussed, especially in terms of reproducibility and stability. Gelatin and casein hydrolysis were found to be especially unstable properties, and frequently lost during maintenance in broth culture, such 'loss variants' assuming characteristics of the 'intermediate types'. Reasons for some of the variable results are suggested. The use of single carbon-energy sources as taxonomic criteria is discussed. Indefinite results obtained here for the utilization of some single carbon-energy substrates were investigated further to see whether mutants, phenotypic adaptations or contaminants, were involved.

A survey of the literature concerning the taxonomy of the saprophytic fluorescent pseudomonads, together with all the experimental data acquired by the author since 195I, has led to the conclusion that it is now neither possible nor useful to differentiate the three 'species' aeruginosa, fluorescens and putida owing to the frequency of many intermediate types and the possession of a significant common and partially interchangable gene pool. The species name $P$. fluorescens Migula 1895 is suggested for this complex, within which certain strains may be recognized as a mesophilic ecotype, variety aeruginosa, definable as members of the complex with one polar flagellum and able to grow at $42^{\circ}$ but not at $4^{\circ}$. Potential human pathogenicity is not confined to $P$. Aluorescens var. aeruginosa in this species complex. The validity of $\boldsymbol{P}$. aureofaciens and $\boldsymbol{P}$. chlororaphis as separate species is also mentioned.

Some suggestions are made for the future studies of the fluorescent pseudomonads, with especial reference to their crucial ecological characteristics which should be investigated physiologically and genetically, and possibly exploited taxonomically. 
Genome Size Determinations of Microbial DNA by Renaturation - Methodological Considerations. By C. Christiansen, A. Leth BaK and A. Stenderup (University of Aarhus, Aarhus, Denmark)

Kinetic interpretation of DNA renaturations have during the most recent years become of value for measurements of genome sizes in micro-organisms. However, the approach to the method varies considerably making comparisons of the results difficult.

The renaturation is usually followed by the accompanying decline in absorbancy at $260 \mathrm{~nm}$, and either the $C_{0} t$ plot, introduced by Britten \& Kohne ((1966), Carnegie Institution of Washington Year Book 65, 78) or the regular second-order rate plot of Wetmur and Davidson is used for the determination of the reaction rate constant. The first of the two methods requires the reaction to be followed for more than $50 \%$ of the course. As the reaction, because of concatenation, is normally not strictly second-order for more than $30-40 \%$ the $C_{0} t$ plot may have limited applicability. Furthermore, studies on the renaturation of yeast genomes indicate that repeated base sequences with relatively high complexity are not discovered when the $C_{0} t$ plot is used. Episomal DNA may act as repeated sequences in renaturation of bacterial DNA. This possible effect may be hidden if the initial part of the reaction is not followed and a $C_{0} t$ plot used. For these reasons we conclude that in such instances the regular second-order rate plot with calculation of initial reaction rates is the most useful of the two methods.

Very contradictory results have been presented concerning the effect of the GC content of the DNA on the reaction rates. Our data on renaturation of bacterial, mycoplasmal and yeast DNAs indicate that the effect of base composition is not very large and without much practical significance.

DNA Base Composition and DNA Homology of Coryneform Bacteria, Isolated from Soil, Cheese and Sea Fish. By W. H. J. CromвACH (Lab. voor Microbiologie, Landbouwhogeschool, Wageningen, The Netherlands)

The mean DNA base composition ( $\% \mathrm{GC})$ has been determined of 34 representative strains of coryneform bacteria, isolated from soil, cheese and sea fish. For comparison, 20 named cultures of the genera Arthrobacter, Brevibacterium, Mycobacterium, Corynebacterium and Nocardia have been included.

DNA was purified according to the method of Marmur, J. ((1961), Journal of Molecular Biology 3, 208), modified for the present study. The $\%$ GC values were estimated with the thermal denaturation method. Hybridization experiments were carried out using the procedure of De Ley, J., Cattoir, H. \& Reynaerts, A. ((1970), European Journal of Biochemistry 12, 133).

According to a preliminary morphological and physiological study, the isolated coryneform bacteria could be divided into three groups:

Group I: Io soil coryneforms, identified as arthrobacters, supplemented with 2 Arthrobacter globiformis strains.

Group II: II orange coryneforms, isolated from cheese and from sea fish, supplemented with 2 Brevibacterium linens strains.

Group III: 13 non-orange cheese coryneforms.

The $\%$ GC values of the strains of group I range from 65.3 to 67.0 , which means that this group may be genetically homogeneous. As to their DNA base composition, the strains of group II may also be genetically closely related, except for one isolate, their \% GC values covering a narrow range from 62.6 to 64.0 . This would mean that the sea-fish coryneforms are closely related with the orangecheese coryneforms of the Brevibacterium linens type. However, hybridization experiments showed only a slight relationship between Brevibacterium linens and the sea-fish coryneforms (degree of duplexing, $D$, approximately $20 \%$, whereas a close relationship was found to exist among the representative orange-cheese coryneforms, including Brevibacterium linens ( $D$ approximately $85 \%$ ). The majority of the non-orange-cheese coryneforms may be genetically closely related, as their $\%$ GC values show a narrow range from 65.5 to 66.9 . The $\% \mathrm{GC}$ values of three isolates of this group deviate markedly from the latter range, which is in agreement with the low $D$ value (15\%) between a representative strain of these three isolates and one of the majority of isolates of group III.

Preliminary results of hybridization experiments between representative strains of groups I, II and III indicate a slight genetic relationship between the soil arthrobacters and the orange-cheese coryneforms ( $D$ approximately $15 \%$ ) and similarly between the orange-cheese coryneforms and the majority of strains of the non-orange-cheese coryneforms ( $D$ approximately $15 \%$ ). 
Properties of Deletion Mutants of Citrobacter freundii Infected with a F'gal Plasmid. By J. DE GraAFF and A. Stouthamer (Lab. voor Microbiologie der V.U., Amsterdam, The Netherlands)

Chlorate-resistant mutants of Citrobacter freundii are unable to form nitrate reductase A, thiosulphate reductase, tetrathionate reductase, and formate dehydrogenase. By deletion analysis the gene order gal-chl D-hut-bio-uvr B-chl A was found. After transfer of the temperature-sensitive plasmid $F_{t s .114}$ nad $A$ aro $\mathrm{G}$ gal att $\lambda$ bio uvr $\mathrm{B}$ to mutants with an extended deletion in the gal-bio region some properties of the $E$. coli donor appear: production of indole and lysine decarboxylase, fermentation of dulcitol and sensitivities for the bacteriophages $T$ I, $T 5$ and $T 6$. At the same moment the sensitivity to six Citrobacter bacteriophages is lost. Elimination of the plasmid by treatment with acridine orange results in a loss of these $E$. coli donor properties. When the plasmid is introduced in Citrobacter strains with a smaller deletion in the same region, none of these properties is observed. Various fragments of this plasmid can be integrated into the chromosome. Depending on the fragment integrated, some of the E. coli properties remain. Elimination of the temperaturesensitive plasmid by subculturing at $37^{\circ}$ sometimes resulted in the appearance of new auxotrophic deficiencies. Requirements for $a r g, i l v$, trp and gua have been detected. In only one of these mutants part of the chromosomal markers of the plasmid can still be detected. All these mutants are unstable, segregating prototrophic strains or strains deficient for one of the other deficiencies. For instance, a strain $\mathrm{arg}^{-} \mathrm{gua}^{+}$segregates both $\mathrm{arg}^{+} \mathrm{gua}^{+}$and $\mathrm{arg}^{+} \mathrm{gua}^{-}$. These results are explained by the hypothesis that during growth at $37^{\circ}$ parts of the plasmid can be unstably integrated at a number of definite places on the chromosome by which inactivation of genes occurs.

Circular DNA Molecules in Escherichia coli Possessing the Surface-antigen K88. By A. Leth BAK, Gunna Christiansen, C. Christiansen and A. Stenderup (University of Aarhus, Aarhus, Denmark) and IDA ØRSKOV and F. ØRSKOV (Statens Seruminstitut, Copenhagen, Denmark)

Genetic studies of $\mathbf{R}$-factors in enterobacteria have shown that the transfer factor and the resistance determinants can exist as independent replicons and can be transferred either separately or as an integrated unit (Anderson, E. S. (1968), Annual Review of Microbiology 22, I3I; Smith, H. W. \& Gyles, C. L. (1970), Journal of General Microbiology 62, 277). The conclusions in these works are supported by studies of the molecular nature of isolated R-factor DNA. The demonstration of three different size classes of supercoiled circular DNA molecules in some enterobacteria harbouring $\mathbf{R}$-factors, also support the idea of a possible dissociation of a composite R-factor into a transfer factor and a resistance determinant (Cohen, S. N. \& Miller, C. A. (1970), Journal of Molecular Biology 50, 671 ; Silver, R. P. \& Falkow, S. (1970), Journal of Bacteriology 104, 339; Nisioka, T., Mitani, M. \& Clowes, R. C. (1969), Journal of Bacteriology 98, 370).

We have studied the molecular nature of the episomal DNA in four strains of $E$. coli possessing different combinations of ability to produce the K88 surface antigen and ability to transfer this character (Ørskov, I. \& Ørskov, F. (1966), Journal of Bacteriology 91, 69). Labelled episomal DNA was purified by filtration of the alkaline denaturated whole cell DNA through nitrocellulose membrane filters followed by centrifugation in ethidium-bromide $\mathrm{CsCl}$ density gradients. The purified DNA was studied by sucrose-gradient sedimentation, electron microscopy and analytical $\mathrm{CsCl}$ density-gradient centrifugation.

All the episomal DNA from the four strains formed a single band in the $\mathrm{CsCl}$ gradient at a density of $1.709 \mathrm{~g} . / \mathrm{cm}^{3}{ }^{3}$ Both sucrose-gradient analysis and electron microscopy revealed three size classes of circular DNA molecules in one of the strains studied. The length of the open circles as measured on the electron-microscopic pictures were 5,20 and $25 \mu \mathrm{m}$. The three other strains contained different amounts of the two largest species, but no $5 \mu \mathrm{m}$ long circles. The results seem to support the theory of a possible dissociation of composite episomes. 
The Selective Detection of Pseudomonas aeruginosa in Water. By D. A. A. Mossel and CARLA VAN ZADELHOFF (Centraal Institut voor Voedingsonderzoek, Zeist, The Netherlands)

In a previous study it was demonstrated that Pseudomonas aeruginosa can be detected in water by enrichment at $42^{\circ}$ in crystal violet-tylosin-kanamycin broth, followed by plating, also at $42^{\circ}$, on to glycerol-mannitol-acetamide-cetrimide-phenol red (GMAC) agar. Absence of attack on glycerol and mannitol under these conditions was found a most consistent criterion for $\boldsymbol{P}$. aeruginosa in a further investigation on 100 strains, despite reports that these polyols may be dissimilated. Also, all strains of $\boldsymbol{P}$. aeruginosa showed growth restricted to approximately the upper $1 \mathrm{~mm}$. area of stabbed tubes of crystal violet-neutral red-bile salts-glucose agar and none failed to assimilate malonate.

However, nine strains amongst 500 recent clinical isolates were found not to grow with alkalinization on GMAC-agar at $42^{\circ}$; six of these $(\mathrm{I} \cdot 2 \%)$ appeared not to possess an acylamidase, which is in good agreement with a recent report of Arai et al. (1970), Journal of General and Applied Microbiology, Tokyo, 14, 279. Only three strains did not resist the combined stress of incubation at $42^{\circ}$ and the presence of $300 \mu \mathrm{g}$. $/ \mathrm{ml}$. cetrimide in the medium. Less than $\mathrm{I} \%$ of the strains did not tolerate $15 \mu \mathrm{g}$./ml. kanamycin, the level used in the medium, which is in agreement with recent data. Generally, therefore, the procedure has a quite satisfactory reliability.

When tested on a solid medium $69 \%$ of the strains were sensitive to $50 \mu \mathrm{g} . / \mathrm{ml}$. gentamicin and $85 \%$ to $100 \mu \mathrm{g} . / \mathrm{ml}$. gentamicin.

\section{Limitations of the Use of Selective Media for the Enumeration of Pseudomonadaceae in Foods, Water and Cosmetics. By J. DE WAART and H. Pouw (Centraal Institut voor Voedingsonderzoek, Zeist, The Netherlands)}

Three different selective media are generally used for the isolation of Pseudomonas species from foods and water. The selective agents applied in these media are: (i) crystal violet; (ii) chloramphenicol plus erythromycin; (iii) penicillin. In addition, special carbon sources, such as starch, lactate, glutamic acid, and arginine, and indicators are used in some of these media, to furnish elective conditions. None of these media is fully satisfactory, due to a low selectivity of some or the complicated preparation of others, and the inhibition of certain types of Pseudomonas species on a few of them.

A new medium: H.P. (Herellea-Pseudomonas) medium is suggested; it is based on the attack of arginine by Pseudomonas while chloramphenicol is the only selective agent used. The medium's selective properties are better than those of the three media mentioned and it is also very easy to prepare. Quantitative recovery of Pseudomonadaceae from five kinds of foods was achieved with the use of this medium. Pseudomonas acidovorans and Pseudomonas putrefaciens, being argininedihydrolase-negative, do not grow on H.P. medium; however, they also develop very poorly on the other media mentioned. Their isolation from food, water and cosmetics requires the primary use of crystal violet agar of Olson and subsequent identification.

Light-Dark Transients in Nitrogen Fixation by Anabaena cylindrica. By M. Donze, H. J. VAN Gorkom and A. J. P. RAAT (Biophysical Laboratory, Leiden, The Netherlands)

In aerobically grown Anabaena cylindrica $\mathrm{N}_{2}$ fixation was studied with the acetylene reduction technique. If samples were incubated in the light under aerobic $\left(10 \% \mathrm{C}_{2} \mathrm{H}_{2}\right.$ in air) or anaerobic ( $10 \% \mathrm{C}_{2} \mathrm{H}_{2}$ in $\mathrm{He}$ ) conditions the rate of $\mathrm{C}_{2} \mathrm{H}_{2}$ reduction in the anaerobic case was slightly higher. However, after switching off the light marked differences occur:

(I) In the anaerobic sample acetylene reduction drops to zero within $2 \mathrm{~min}$., which is about the time resolution of the method. The process can be restored either by readmitting the light or, temporarily, by injections of $\mathrm{O}_{2}$ in the dark. Restoration by light is not affected by DCMU. So we may conclude that dark $\mathrm{N}_{2}$ fixation is strictly $\mathrm{O}_{2}$-dependent, and that $\mathrm{N}_{2}$ fixation in the light is a direct photosynthetic process which can be driven by photosystem I alone. If the light is switched on after about $2 \mathrm{~h}$., the initial rate is higher than the steady state.

(2) In aerobically incubated samples the rate of acetylene reduction after switching off the light drops within a few minutes to about $10 \%$ of the initial value; then rises to a maximum after about 
$20 \mathrm{~min}$. and then declines exponentially to zero with a half-life of about $25 \mathrm{~min}$. Our present working hypothesis accounts for these phenomena in the following way. The initial drop is the abrupt halt of photosynthetic $\mathrm{N}_{2}$ fixation. The $\mathrm{O}_{2}$-dependent reaction apparently requires an activation period, which indicates that this process does not occur in the light. The subsequent decline is caused by exhaustion of a pool of electron donor which can be built up only in the light. The observation that this decline extrapolates back to the initial rate in the light can be explained on the assumption that both light-driven and $\mathrm{O}_{2}$-dependent $\mathrm{N}_{2}$ fixation depend on this pool.

\section{Metabolism of Diatoms in Relation to the Basis of Autotrophy. By K. E. COOKSEY (Institute of Marine and Atmospheric Science, Miami, U.S.A.)}

Diatoms are known with nutritional physiologies which range from obligate photoautotrophy to heterotrophy. Many are capable of mixotrophic growth - a particularly important facet of autotrophic metabolism in view of its position between autotrophy and heterotrophy.

Cocconeis diminuta and Amphora sp. are benthic diatoms isolated from Biscayne Bay, Florida. Cocconeis can assimilate several organic compounds, notably organic acids, into cell constituents and oxidize some of them to $\mathrm{CO}_{2}$. Those compounds which are assimilated stimulate growth in the light but do not promote growth in darkness (Bunt, J. S. (1969), Journal of Phycology 5, 37). Amphora sp. is a facultative heterotroph. It assimilates several organic compounds in light and dark but only glucose supports growth in darkness.

The levels of the Krebs tricarboxylic acid cycle enzymes in photoautotrophically grown Cocconeis are considerably lower than in Amphora sp. Reduced pyridine nucleotide oxidizing ability is much less in the photoautotrophically grown cells than in the heterotrophically grown cells. The results of enzyme assays and labelling patterns are discussed in relation to the basis of obligate autotrophy postulated by Smith, A. J., London, J. \& Stanier, R. Y. (Journal of Bacteriology 94, 972).

Lysis of Gram-negative Bacteria by Compounds Produced by Mycococcus luteus and Xanthomonas hyacynthi. By G. J. J. KORTSTEE (Lab. voor Microbiologie, Landbouwhogeschool, Wageningen, The Netherlands)

(I) $M$. luteus and $X$. hyacinthi have been shown to produce extracellular compounds lysing (as measured by turbidity reduction) a wide variety of Gram-negative bacteria.

(2) Formation of the lytic activity in $M$. luteus was maximal in the early log phase. Maximum activity was found in entering the stationary growth phase. After attaining this phase a rapid decline occurred. In $X$. hyacinthi the lytic activity was roughly proportional to the growth, and remained constant during the stationary growth phase.

(3) Lysis of whole cells and cell walls of E. coli and $P$. fuorescens by the culture liquors depended on the ionic strength of the incubation medium. Cells of log phase cultures of $P$. fluorescens were less susceptible than those of the stationary growth phase. In all instances, resistant cells or walls of these organisms became susceptible by heating. Lysis of whole cells or walls by egg-white lysozyme could only be achieved by including EDTA in the incubation medium.

(4) Muramic acid, glucosamine and diaminopimelic acid were readily detectable upon hydrolysing the fragments released by incubation of $E$. coli walls with the lytic compounds. Because preparations of the fragments released were heavily contaminated with protein, alanine and glutamic acid present in these fragments could not be determined accurately. Therefore, partially purified glycosaminepeptide was incubated with the lytic compounds.

With the exception of a bacteriolytic myxobacter enzyme, which lysed only three Gram-negative bacteria, none of the bacteriolytic enzymes isolated so far from cultures of a wide variety of microorganisms attacked Gram-negative bacteria. The above results indicate that bacteria are also capable of producing lytic compounds which attack Gram-negative bacteria. Recently Martin \& Kemper (1970), Journal of Bacteriology 102, 347, provided evidence for the presence of a lytic enzyme in a commercial preparation of phospholipase $\mathrm{C}$ of Clostridium perfringens which acted on cell walls of $E$. coli and Spirillum serpens. 
Some Quantitative Aspects of the Incorporation of Organic Compounds by Two Obligately Chemolithotrophic Sulphur Bacteria. By J. G. KUENEN and H. VeLDKAMP (Lab. voor Microbiologie, Groningen, Haren, The Netherlands)

In thiosulphate-limited continuous cultures of a newly isolated obligately chemolithotrophic spirillum (Kuenen, J. G. \& Veldkamp, H. (1970), Antonie van Leeuwenhoek 36, 186), the effect of organic compounds added to the autotrophic medium containing minerals + thiosulphate was investigated. Acetate ( $1 \mathrm{~mm}$ ) caused an increase in dry weight and cellular protein of $15 \%$ and $12 \%$, respectively. For $T$. thioparus these figures were $14 \%$ and $17 \%$, respectively.

Succinate (I $\mathrm{mM}$ ) increased the cell yield by $15 \%$; I mM acetate plus I mM succinate had a concerted effect and caused a $24 \%$ increase in dry weight and $27 \%$ increase in protein in the spirillum, and $22 \%$ resp. $40 \%$ in $T$. thioparus.

Glutamate, aspartate, casamino acids, glycine, but not glucose, fructose, glycerol, glycerate, lactate, pyruvate, malate or ribose caused similar effects.

Although these quantitative effects of organic compounds on cell yields and protein content could be established, no differences could be measured between the levels of carboxydismutase activity in cell-free extracts obtained from chemostat cultures grown autotrophically or in the presence of organic compounds.

Demethylation of Trimethylamine $\boldsymbol{N}$-oxide by Pseudomonas aminovorans. By P. J. LARGE (University of Hull, Hull, Great Britain)

Pseudomonas aminovorans NCIB9039, first isolated by den Dooren de Jong, L. E. ((1927), Zentralblatt für Bakteriologie, Abt. II, 7r, 193), will grow on a number of methyl amines, including trimethylamine $\mathrm{N}$-oxide, as sole carbon source. It is one of a limited group of organisms able to grow on $C_{1}$ compounds as sole carbon source (Quayle, J. R. (1963), Journal of General Microbiology 32, 163 ). The problem of growth on $\mathrm{C}_{1}$ compounds and its relevance to autotrophy has been discussed (Qúayle, J. R. (1961), Annual Review of Microbiology 15, I19). Pseudomonas aminovorans grown on trimethylamine $N$-oxide oxidizes methylamine, dimethylamine, trimethylamine $N$-oxide and formate without a lag. Extracts contain an enzyme which catalyses the non-oxidative, nonhydrolytic conversion of trimethylamine $\mathrm{N}$-oxide into dimethylamine and formaldehyde. The unstable enzyme has been purified about fivefold.

The partially purified preparation can be freed from dimethylamine oxidase activity (Eady, R. R. \& Large, P. J. (1969), Biochemical Journal III, 37P) by ageing, since the latter enzyme is less stable. Unlike the dimethylamine oxidase, the demethylase activity is not inhibited by carbon monoxide or thiol compounds, although cyanide is a potent inhibitor. A similar enzyme has recently been described in Bacillus PM6 (Myers, P. A. \& Zatman, L. J. (1971), Biochemical Journal 121, IOP), although the Pseudomonas aminovorans enzyme differs in many respects - for example, its $\mathrm{pH}$ optimum is 6.0 compared with 7.5 and the response to inhibitors is different. The enzyme is also present in Pseudomonas aminovorans grown on methylamine, dimethylamine or trimethylamine.

When succinate-grown bacteria were transferred to methylamine growth medium there was a tenfold increase in specific activity in the lag period of $24 \mathrm{~h}$. before growth on methylamine began. We suggest that the enzyme plays an important role in growth on trimethylamine $N$-oxide and trimethylamine, although its presence in bacteria grown on dimethylamine and methylamine is difficult to explain. 